Case Report

\title{
Quality of Life Following Early Orthodontic Therapy for Anterior Crossbite: Report of Cases in Twin Boys
}

\author{
Eluza Piassi, ${ }^{1}$ Leonardo Santos Antunes, ${ }^{2}$ \\ Marcia Rejane Thomas Canabarro Andrade, ${ }^{2}$ and Lívia Azeredo Alves Antunes ${ }^{2}$ \\ ${ }^{1}$ Fluminense Federal University, Niterói, RJ, Brazil \\ ${ }^{2}$ Department of Specific Formation, School of Dentistry, Fluminense Federal University, Nova Friburgo, RJ, Brazil
}

Correspondence should be addressed to Lívia Azeredo Alves Antunes; liviaazeredo@gmail.com

Received 5 July 2016; Accepted 1 September 2016

Academic Editor: Maria Beatriz Duarte Gavião

Copyright (C) 2016 Eluza Piassi et al. This is an open access article distributed under the Creative Commons Attribution License, which permits unrestricted use, distribution, and reproduction in any medium, provided the original work is properly cited.

\begin{abstract}
Anterior crossbite (AC) refers to a condition in which the maxillary anterior teeth are placed lingually in their relationship with the mandibular anterior teeth. This dental condition results in visible incisor differences that are associated with higher levels of dissatisfaction with appearance and have potential to negatively impact on oral health-related quality of life (OHRQoL) of the children. The aim of this paper was to report two cases of interceptive orthodontic treatment of twin children with anterior crossbite and its impact on OHRQoL of these children. Although AC affects negatively psychosocial aspects of OHRQoL of the children, the interceptive orthodontic treatment of children with AC was essential to improve their OHRQoL.
\end{abstract}

\section{Introduction}

Anterior crossbite (AC) refers to a condition in which the maxillary anterior teeth are placed lingually in their relationship with the mandibular anterior teeth [1]. The prevalence reported in the literature ranges from $0.5 \%$ to $11.9 \%$ [2-6], depending on the age of the child, ethnic group, and also methods of registration [7].

An anterior crossbite may be regarded as an aesthetic problem and is a malocclusion that is established and is presented in the mixed dentition $[8,9]$. Since it is seldom selfcorrected, it should be treated as soon as possible, because it can develop into a more severe malocclusion or cause traumatic injury to the periodontal tissues [1]. Moreover, this dental condition results in visible differences in the incisors which are associated with higher levels of dissatisfaction with appearance and may cause a negative impact on oral healthrelated quality of life (OHRQoL) of the children [10].

Several methods of assessing the OHRQoL of the children are available such as $\mathrm{CPQ}_{11-14}$ [11], $\mathrm{CPQ}_{8-10}$ [12], Child OIDP [13], ECOHIS [14], and SOHO [15]. The original $\mathrm{CPQ}_{8-10}$ was developed and validated in Canada and measures the negative effects of orofacial conditions on the social, emotional, and functional wellbeing of children between 8 and 10 years of age [12]. However, the $\mathrm{CPQ}_{8-10}$ has been tested and validated in other countries [16-19].

Several treatment options such as fixed and/or removable appliances, which act directly on the malpositioned teeth, have been devised for early interceptive treatment of the anterior crossbite [20]. A systematic review performed in 2011 disclosed a wide variety of treatment modalities for anterior crossbite correction in the primary dentition or the mixed dentition. Although the level of evidence observed was low to support any technique, there was similarity in the length of time it took to successfully treat anterior crossbites [9].

Therefore, the interceptive orthodontic treatment of anterior crossbite should be carried out in the early mixed dentition with the aim of preventing the development and progression of tooth malalignments and malocclusions and to avoid negative effects on OHRQoL of children [2, 21].

Based on the above mentioned data, the aim of this paper was to report two cases of early orthodontic therapy in twin children with anterior crossbite and its impact on OHRQoL of these children. 


\section{Case Report}

Seven-year-old twin boys with anterior crossbite (AC) in permanent teeth were referred to the Preventive/Interceptive Orthodontic Clinic of a Public Dental Service, Rio de Janeiro, Brazil.

A comprehensive clinical examination did not reveal skeletal discrepancies. On manipulation of the mandibles, the incisors obtained an end-to-end relationship, indicative of a dental problem. The canines were in class I occlusion in both cases. About the patient's medical histories, the children were born by cesarean delivery with 36 months of age and normal birth weights $(\geq 2500 \mathrm{~g})$. Both children had breastfeeding for 3 months only and bottle feeding until 3 years of age. They had a dummy-sucking habit until four years of age.

The treatment plan to two children consisted of the interceptive orthodontic treatment with removable plates with springs. In two cases there was sufficient mesiodistal distance to move the upper tooth towards the labial. The legal guardians signed an informed consent form for treatment.

The impact of a children's oral condition on their OHRQoL was measured using the Brazilian version of the Child Perceptions Questionnaire $\left(\mathrm{CPQ}_{8-10}\right)$ [16]. The $\mathrm{CPQ}_{8-10}$ is a questionnaire that was developed to assess the impact of oral condition on OHRQoL of children aged 8 to 10 years [16]. This instrument was applied in two different points in time (Table 1): T1: first appointment; T2: after finalized treatment.

The questionnaire contains 25 items organized into 4 health domains: oral symptoms (five items); functional limitations (five items); emotional wellbeing (five items); and social wellbeing (10 items). The items have five Likert response options: "never: 0 ," “once or twice: 1 ," "sometimes: 2," “often: 3," and "every day or almost every day: 4." The total $\mathrm{CPQ}_{8-10}$ score and those for subscales are calculated by summing all the item scores; higher scores indicate that the oral conditions have a greater negative impact on the child's OHRQoL [16]. The question "Why?" was added to the items of each subscale of $\mathrm{CPQ}_{8-10}$ when the oral condition caused some impact.

2.1. Case 1. The first boy presented anterior dental crossbite $(\mathrm{ACB})$ in the upper right central incisor. The clinical exam revealed that the patient was in good health and had no caries experience. A panoramic radiograph revealed no abnormality. Impressions of both arches were taken using alginate and study models made with plaster. The removable appliance was manufactured using acrylic resin, with a protrusion spring for each incisor in anterior crossbite, bilateral occlusal coverage of the posterior teeth, and an expansion screw. The protrusion springs were activated once a month until normal incisor overjet was achieved. The screw was activated during the treatment period only if it was judged to comply with the natural transverse growth of the jaw. The dentist instructed the patient firmly to wear day and night the appliance, except for meals, toothbrushing, and physical activities. The progress was evaluated every 4 weeks. Dental crossbite correction was achieved within the first 3 months of treatment (Figures 1(a), 1(b), 1(c), and 1(d)). The same
TABLE 1: Total and subscale $\mathrm{CPQ}_{8-10}$ scores at two different points in time.

\begin{tabular}{|c|c|c|c|c|}
\hline \multirow{2}{*}{ Domains } & \multicolumn{2}{|c|}{ Case one } & \multicolumn{2}{|c|}{ Case two } \\
\hline & $\mathrm{T} 1$ & $\mathrm{~T} 2$ & $\mathrm{~T} 1$ & $\mathrm{~T} 2$ \\
\hline \multicolumn{5}{|l|}{ Oral symptoms } \\
\hline Toothache & 0 & 0 & 0 & 0 \\
\hline Mouth sores & 0 & 0 & 0 & 0 \\
\hline Pain upon ingesting cold food & 0 & 0 & 0 & 0 \\
\hline Food trapped in teeth & 0 & 0 & 0 & 0 \\
\hline Bad smell in mouth & 0 & 0 & 0 & 0 \\
\hline \multicolumn{5}{|l|}{ Functional limitations } \\
\hline Time for eating & 0 & 0 & 0 & 0 \\
\hline Difficulty biting and/or chewing & 0 & 0 & 0 & 0 \\
\hline Difficulty eating & 0 & 0 & 0 & 0 \\
\hline Trouble talking & 0 & 0 & 0 & 0 \\
\hline Difficulty sleeping & 0 & 0 & 0 & 0 \\
\hline \multicolumn{5}{|l|}{ Emotional wellbeing } \\
\hline Bothered & 2 & 0 & 1 & 0 \\
\hline Sad & 2 & 0 & 2 & 0 \\
\hline Ashamed & 2 & 0 & 1 & 0 \\
\hline Worried & 2 & 0 & 0 & 0 \\
\hline Nice & 4 & 0 & 0 & 0 \\
\hline \multicolumn{5}{|l|}{ Social wellbeing } \\
\hline Child missed school & 0 & 0 & 0 & 0 \\
\hline Trouble doing homework & 0 & 0 & 0 & 0 \\
\hline Trouble paying attention in class & 0 & 0 & 0 & 0 \\
\hline Trouble talking or reading in class & 0 & 0 & 0 & 0 \\
\hline Child avoided smiling or laughing & 0 & 0 & 1 & 0 \\
\hline Child avoided talking & 0 & 0 & 0 & 0 \\
\hline Child avoided other children & 0 & 0 & 0 & 0 \\
\hline Staying out of games & 0 & 0 & 0 & 0 \\
\hline Victim of name-calling & 0 & 0 & 0 & 0 \\
\hline Questions about teeth & 0 & 0 & 0 & 0 \\
\hline Total B-CPQ $Q_{8-10}$ score & 12 & 0 & 5 & 0 \\
\hline
\end{tabular}

T1: first appointment; T2: after finalized treatment.

appliance then served as a passive retainer for a retention period of 3 months.

2.2. Case 2. Another boy presented ADC in the two upper central incisors. An exam revealed that the patient was in good health and had caries experience. A panoramic radiograph revealed no abnormality. After impression, the same standards of procedure were followed as in the first case. The protrusion springs were activated once a month, until the normal incisor overjet was achieved. The screw was activated during the treatment period only if it was judged to comply with the natural transverse growth of the jaw. The dentist instructed the patient firmly to wear day and night the appliance, except for meals, toothbrushing, and physical activities. The progress was evaluated every 4 weeks. Dental crossbite correction was achieved within the first 5 months of treatment (Figures 2(a), 2(b), 2(c), and 2(d)). The same 


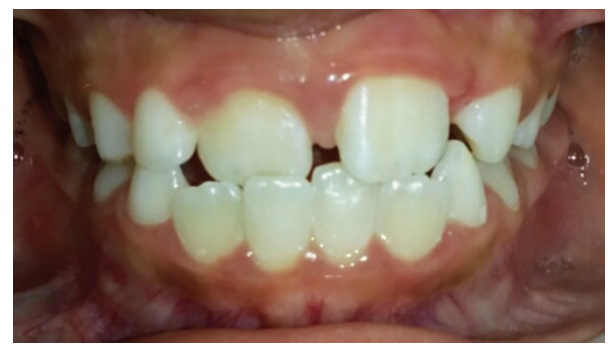

(a)

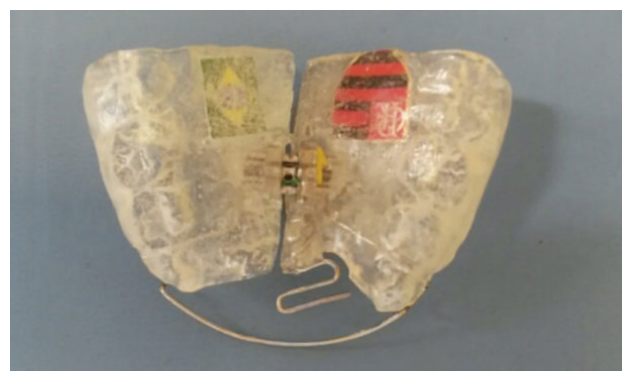

(c)

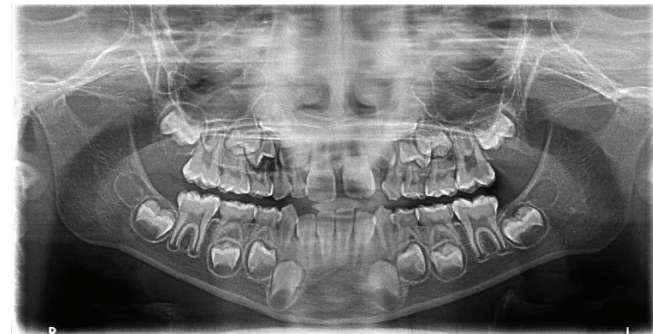

(b)

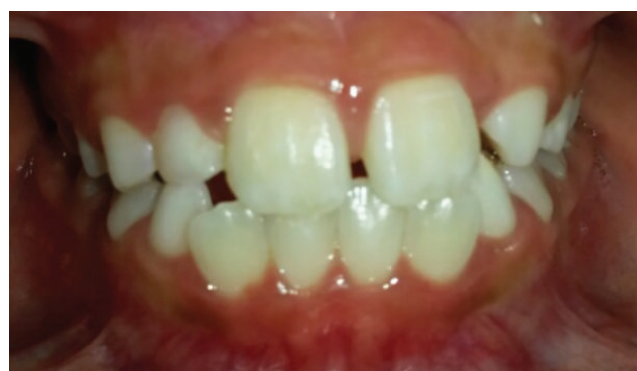

(d)

Figure 1: Case 1. (a) Anterior dental crossbite in the upper right central incisor. (b) Panoramic radiograph showing no abnormality. (c) Removable orthodontic appliance with a protrusion spring for incisor in anterior crossbite. (d) Anterior crossbite correction after 3 months.

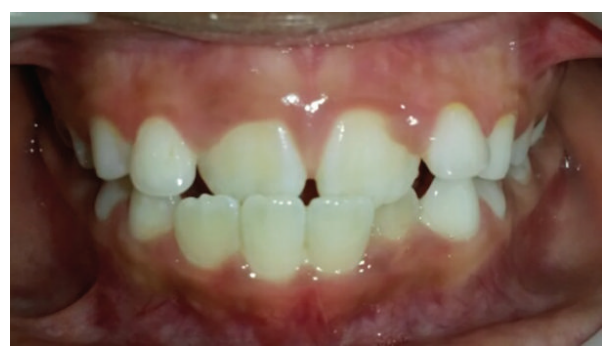

(a)

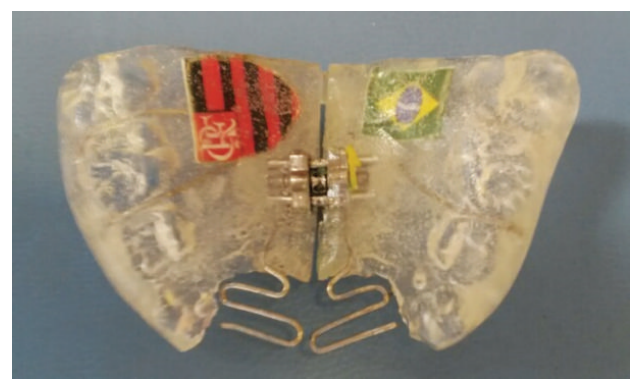

(c)

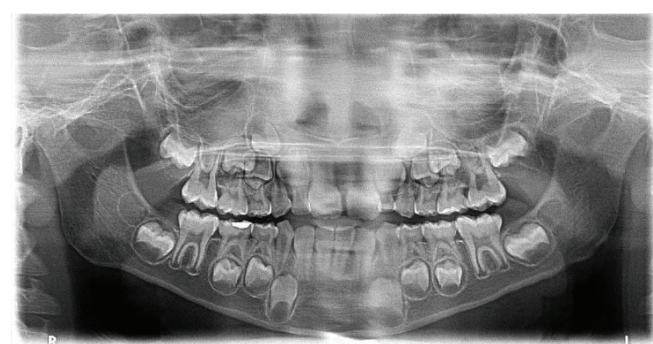

(b)

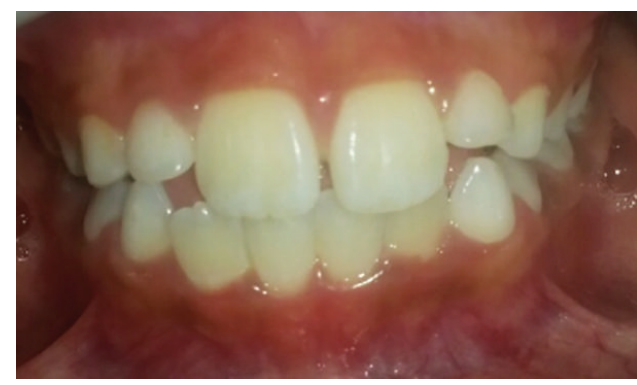

(d)

FIgURE 2: Case 2. (a) Anterior dental crossbite in the two upper central incisors. (b) Panoramic radiograph showing no abnormality. (c) Removable orthodontic appliance with a protrusion spring for each incisor in anterior crossbite. (d) Anterior crossbite correction after 5 months.

appliance then served as a passive retainer for a retention period of 3 months.

Six months later patients were recalled again to assess relapse. In addition, periapical radiographs were taken and no periapical pathology was evident (Figures 3(a), 3(b), 3(c), $3(\mathrm{~d})$, and $3(\mathrm{e}))$.

\section{Discussion}

Anterior crossbite had negative psychosocial effects on OHRQoL of the twin boys, corroborating with a systematic review that reported that malocclusions have negative effects on OHRQoL, predominantly in the of domains emotional 


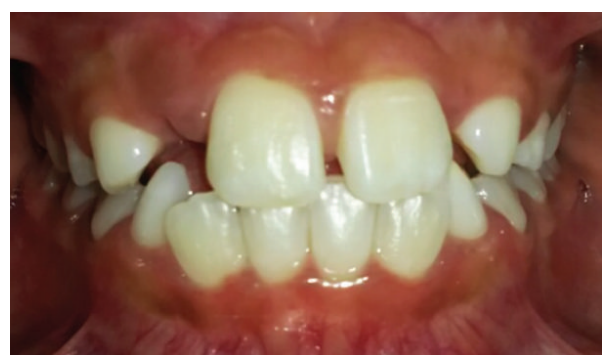

(a)

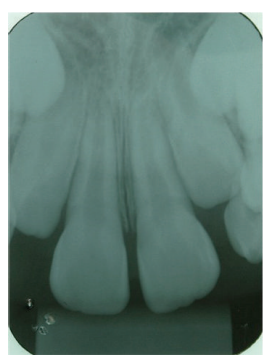

(b)

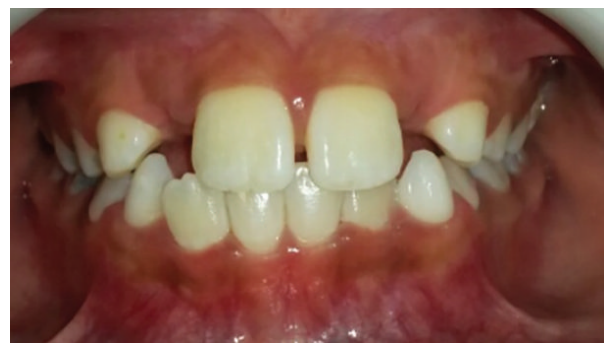

(c)

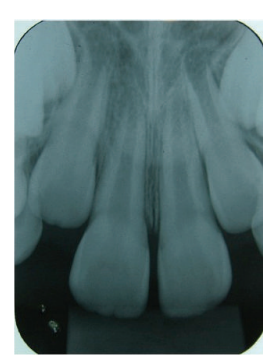

(d)

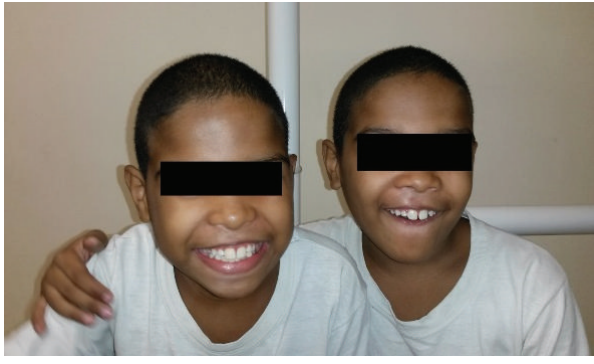

(e)

Figure 3: Six months later, after treatment. (Case 1: (a), (b); Case 2: (c), (d)) Central incisors were in normal position and there was no relapse. Periapical radiographs of upper central incisor teeth. There was no pathological condition ((e): twin boys smiling).

and social wellbeing of children and adolescents [21]. According to Marques et al. [22] and in a recent systematic review [23], malocclusions treatment reduces the impact on children and adolescents' OHRQoL. In this case report it was confirmed; the interceptive orthodontic treatment to correct the anterior crossbite showed the importance of dental esthetics for improvement of a children's OHRQoL.

The differences between $\mathrm{CPQ}_{8-10}$ scores before and after treatment confirmed the success of our chosen therapy. Although the twin boys had a negative impact in the same domain of the questionnaire (emotional wellbeing), the scores were different. Only one boy had a negative impact on social wellbeing domain. A possible explanation of these findings could be that the individuals differ in the evaluation of their dental condition and in the perceived psychological consequences [24]. On the other hand, when the children were solicited to answer the question "Why?" to items of subscale that caused impact, they answered: "because the wrong dental position." Thus, the present case report highlights that malocclusion, especially in the anterior tooth, can compromise a child's psychosocial wellbeing.

In the mixed dentition, anterior crossbite affecting one or more incisors can be successfully corrected by either fixed or removable appliances [20]. Our cases had undergone removable appliance therapy at the mixed dentition stage because Brazilian public dental service does not offer fixed orthodontic treatment.

There is universal agreement that anterior crossbite should be corrected as soon as possible, corresponding to the maturational level of the child $[25,26]$. The patient's compliance is a factor to be considered at the removable appliance selection, since this factor is essential for successful treatment
[27]. The two cases had satisfactory results, showing that the children and their parents were motivated by therapy.

Another factor to be considered at the appliance selection is the stability of anterior crossbite correction. Previous study concluded that, in the mixed dentition, anterior crossbite affecting one or more incisors can be successfully corrected by either fixed or removable appliances with similar longterm stability [20]. The two patients were recalled again to assess relapse six month later. Clinical examination and radiographs revealed no relapse and no periapical pathology. Periodic recalls of the patients until complete eruption of the permanent teeth are also important because mixed dentition stage is characterized by physiological occlusal changes and, at the same time, new occlusal disorders may occur.

Proper diagnosis and treatment planning can produce the most satisfying results during the mixed dentition stage [28]. Our results highlight the importance of the public dental service that favors the access of the children in mixed dentition stage to orthodontic treatment. Thus, patients with AC should be treated in the early mixed dentition stage to help their satisfaction with appearance and social interaction. Further prospective investigations and studies with a representative sample are needed to confirm the impact of anterior crossbite treatment on OHRQoL of the children.

\section{Conclusion}

Although AC affects negatively psychosocial aspects of OHRQoL of the children, the interceptive orthodontic treatment of children with AC was essential to improve their OHRQoL. 


\section{Competing Interests}

The authors declare that they have no competing interests.

\section{References}

[1] M. H. Chow, "Treatment of anterior crossbite caused by occlusal interferences," Quintessence International, vol. 10, no. 2, pp. 5760, 1979.

[2] P. Schopf, "Indication for and frequency of early orthodontic therapy or interceptive measures," Journal of Orofacial Orthopedics, vol. 64, no. 3, pp. 186-200, 2003.

[3] E. Tausche, O. Luck, and W. Harzer, "Prevalence of malocclusions in the early mixed dentition and orthodontic treatment need," European Journal of Orthodontics, vol. 26, no. 3, pp. 237244, 2004.

[4] N. Karaiskos, W. A. Wiltshire, O. Odlum, D. Brothwell, and T. H. Hassard, "Preventive and interceptive orthodontic treatment needs of an inner-city group of 6- and 9-year-old Canadian children," Journal of the Canadian Dental Association, vol. 71, p. 649, 2005.

[5] A. N. Anosike, O. O. Sanu, and O. O. da Costa, "Malocclusion and its impact on quality of life of school children in Nigeria," West African Journal of Medicine, vol. 29, no. 6, pp. 417-424, 2010.

[6] E. G. Goís, M. P. Vale, S. M. Paiva, M. H. Abreu, J. M. SerraNegra, and I. A. Pordeus, "Incidence of malocclusion between primary and mixed dentitions among Brazilian children. A 5year longitudinal study," Angle Orthodontist, vol. 82, no. 3, pp. 495-500, 2012.

[7] L. Dimberg, B. Lennartsson, K. Arnrup, and L. Bondemark, "Prevalence and change of malocclusions from primary to early permanent dentition: a longitudinal study," The Angle Orthodontist, vol. 85, no. 5, pp. 728-734, 2015.

[8] Y. Ge, J. Liu, X. Guo, and J. Han, "A follow-up study of early interceptive treatment of primary anterior crossbites," European Journal of Orthodontics, vol. 33, no. 5, pp. 551-557, 2011.

[9] F. Borrie and D. Bearn, "Early correction of anterior crossbites: a systematic review," Journal of Orthodontics, vol. 38, no. 3, pp. 175-184, 2011.

[10] H. D. Rodd, Z. Marshman, J. Porritt, J. Bradbury, and S. R. Baker, "Oral health-related quality of life of children in relation to dental appearance and educational transition," British Dental Journal, vol. 211, no. 2, article E4, 2011.

[11] A. Jokovic, D. Locker, M. Stephens, D. Kenny, B. Tompson, and G. Guyatt, "Validity and reliability of a questionnaire for measuring child oral-health-related quality of life," Journal of Dental Research, vol. 81, no. 7, pp. 459-463, 2002.

[12] A. Jokovic, D. Locker, B. Tompson, and M. D. Guyatt, "Questionnaire for measuring oral health-related quality of life in eight- to ten-year-old children," Pediatric Dentistry, vol. 26, pp. 512-518, 2004.

[13] S. Gherunpong, G. Tsakos, and A. Sheiham, "Developing and evaluating an oral health-related quality of life index for children; The CHILD-OIDP," Community Dental Health, vol. 21, no. 2, pp. 161-169, 2004.

[14] B. T. Pahel, R. G. Rozier, and G. D. Slade, "Parental perceptions of children's oral health: The Early Childhood Oral Health Impact Scale (ECOHIS)," Health and Quality of Life Outcomes, vol. 5, article 6, 2007.
[15] J. Abanto, G. Tsakos, S. M. Paiva, D. Goursand, D. P. Raggio, and M. Bönecker, "Cross-cultural adaptation and psychometric properties of the Brazilian version of the scale of oral health outcomes for 5-year-old children (SOHO-5)," Health and Quality of Life Outcomes, vol. 11, no. 1, article 16, 2013.

[16] M. T. Martins, F. M. Ferreira, A. C. Oliveira et al., "Preliminary validation of the Brazilian version of the Child Perceptions Questionnaire 8-10," European Journal of Paediatric Dentistry, vol. 10, no. 3, pp. 135-140, 2009.

[17] T. S. Barbosa, M. C. M. Tureli, and M. B. D. Gavião, "Validity and reliability of the child perceptions questionnaires applied in Brazilian children," BMC Oral Health, vol. 9, article 13, 2009.

[18] P. Wogelius, H. Gjørup, D. Haubek, R. Lopez, and S. Poulsen, "Development of Danish version of child oral-health-related quality of life questionnaires (CPQ8-10 and CPQ11-14)," BMC Oral Health, vol. 22, article 11, 2009.

[19] L. A. F. Foster Page, D. Boyd, and W. M. Thomson, "Do we need more than one Child Perceptions Questionnaire for children and adolescents?" BMC Oral Health, vol. 13, article 25, 2013.

[20] A.-P. Wiedel and L. Bondemark, "Stability of anterior crossbite correction: a randomized controlled trial with a 2-year followup," The Angle Orthodontist, vol. 85, no. 2, pp. 189-195, 2015.

[21] L. Dimberg, K. Arnrup, and L. Bondemark, "The impact of malocclusion on the quality of life among children and adolescents: a systematic review of quantitative studies," European Journal of Orthodontics, vol. 37, no. 3, pp. 238-247, 2015.

[22] L. S. Marques, M. L. Ramos-Jorge, S. M. Paiva, and I. A. Pordeus, "Malocclusion: esthetic impact and quality of life among Brazilian schoolchildren," American Journal of Orthodontics and Dentofacial Orthopedics, vol. 129, no. 3, pp. 424-427, 2006.

[23] E. Piassi, L. S. Antunes, and L. A. A. Antunes, "Orthodontic treatment reduces the impact on children and adolescents' oral healthrelated quality of life," Indian Journal of Dental Research (IJDR), vol. 27, no. 2, pp. 213-219, 2016.

[24] U. Klages, A. Bruckner, and A. Zentner, "Dental aesthetics, self-awareness, and oral health-related quality of life in young adults," European Journal of Orthodontics, vol. 26, no. 5, pp. 507514, 2004.

[25] S. Sari, H. Gokalp, and S. Aras, "Correction of anterior dental crossbite with composite as an inclined plane," International Journal of Paediatric Dentistry, vol. 11, no. 3, pp. 201-208, 2001.

[26] M. Rosa, P. Lucchi, L. Mariani, and A. Caprioglio, "Spontaneous correction of anterior crossbite by RPE anchored on deciduous teeth in the early mixed dentition," European Journal of Paediatric Dentistry, vol. 13, no. 3, pp. 176-180, 2012.

[27] G. Vadiakas and A. D. Viazis, "Anterior crossbite correction in the early deciduous dentition," American Journal of Orthodontics and Dentofacial Orthopedics, vol. 102, no. 2, pp. 160-162, 1992.

[28] M. Suresh, A. Ratnaditya, V. Kattimani, and S. Shameem Karpe, "One phase versus two phase treatment in mixed dentition: a critical review," Journal of International Oral Health, vol. 7, no. 8, pp. 144-147, 2015. 


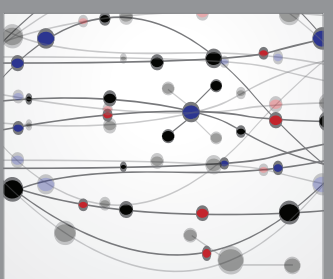

The Scientific World Journal
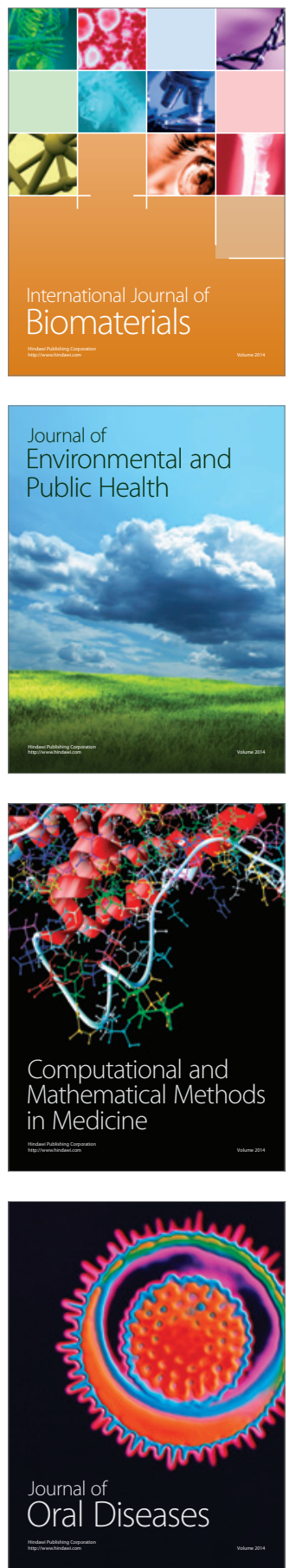
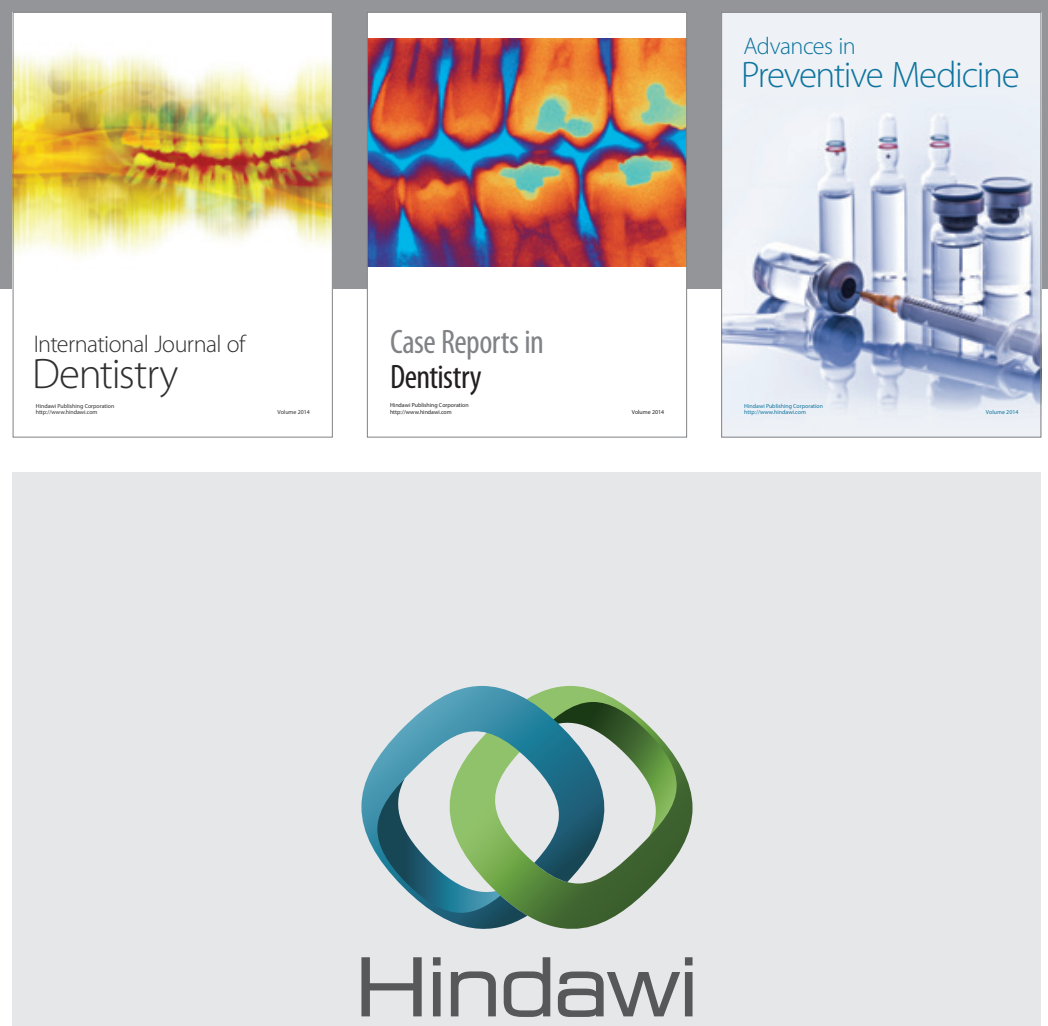

Submit your manuscripts at

http://www.hindawi.com
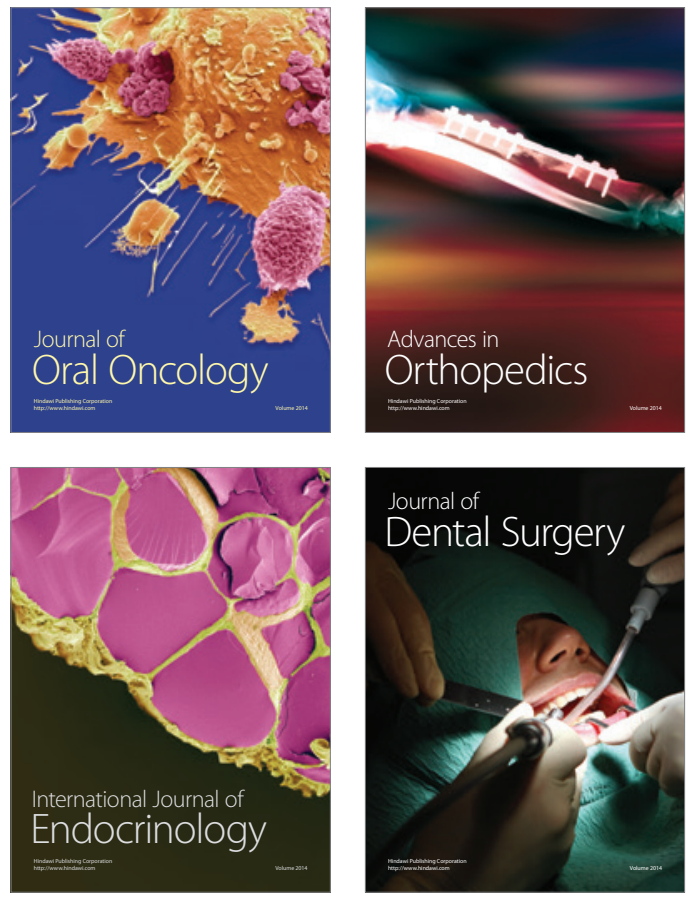
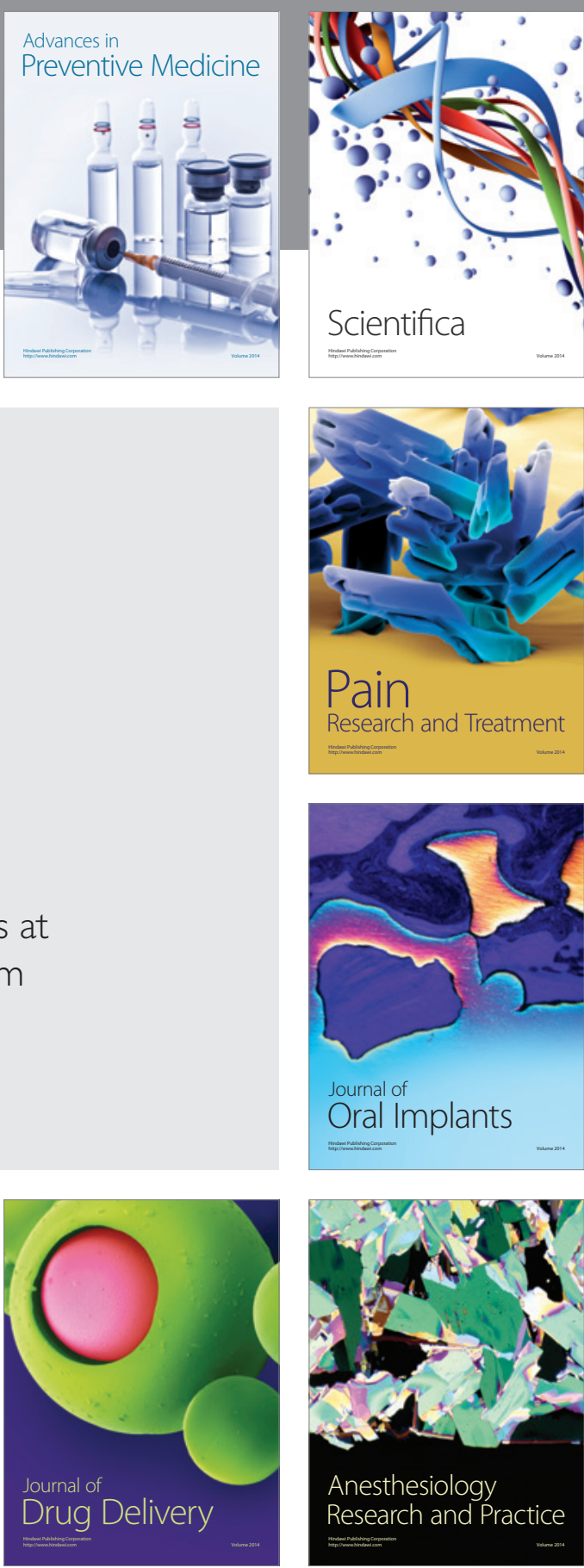

Scientifica
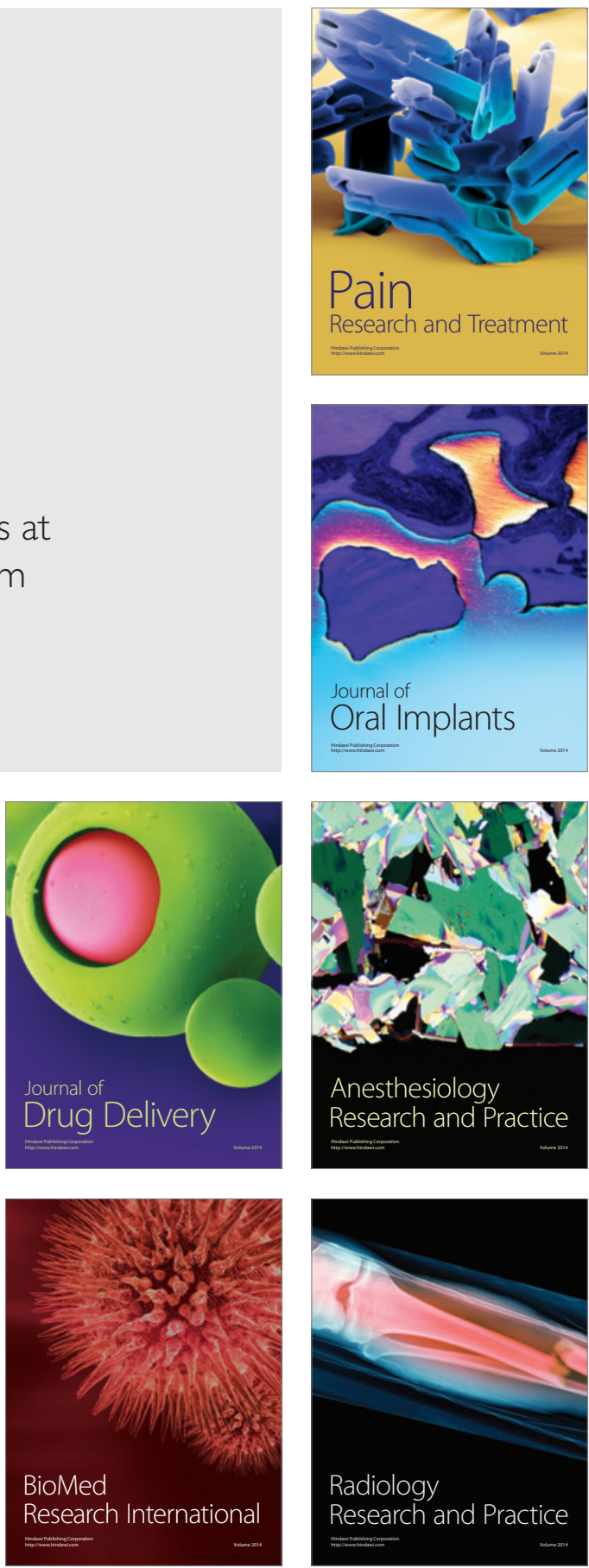